\title{
Development of Amperometric Biosensor Based on Tyrosinase Immobilized in Phosphate-Doped Polypyrrole Film for Detection of Biogenic Amines
}

\author{
Irina Mirela Apetrei ${ }^{1}$, Dana Tutunaru ${ }^{1}$, Claudia-Veronica Popa (Ungureanu) ${ }^{2}$, Constantin Apetrei ${ }^{3}$ \\ ${ }^{1}$ Faculty of Medicine and Pharmacy, "Dunarea de Jos" University of Galati, Romania \\ ${ }^{2}$ Faculty of Food Science and Engineering, "Dunarea de Jos" University of Galati, Romania \\ ${ }^{3}$ Department of Chemistry, Physics and Environment, Faculty of Sciences and Environment, \\ "Dunarea de Jos" University of Galati, 47 Domneasca Street, 800008 Galati, Romania. \\ E-mail: apetreic@ugal.ro
}

\begin{abstract}
:
An electrochemical tyrosinase electrode for detection of tyramine and dopamine was developed via cross-linking immobilization method in phosphate-doped polypyrrole film. The enzyme tyrosinase preserves its biocatalytic activity well within the polypyrrole thin film. Tyramine and dopamine were determined by the direct reduction of biocatalytically formed dopaquinone species at $-0.250 \mathrm{~V}$. The analytical characteristics of this biosensor, including linear range, detection limit, and storage stability are described. For both biogenic amines analyzed, the kinetics of the enzymatic reaction fitted into a Michaelis-Menten type kinetics. The sensitivity followed the decreasing order dopamine>tyramine. The greater value of maximum velocity rate and the lowest Michaelis-Menten constant was found for dopamine.
\end{abstract}

Key words: tyrosinase, biosensor, polypyrrole, tyramine, dopamine

\begin{abstract}
Introduction
Biogenic amines are usually used as quality markers of foods because of their impact on human health if present in food at high concentration levels [1]. These compounds are biosynthesized in plant and in animal cells and formed by microbial decarboxylation of aminoacids. Physiologic active amines (histamine, serotonin, tyramine, and dopamine) are naturally present in vegetables foods. In animal foods, the biogenic amines formed are toxic (putresceine, cadaverine) [2]. Quantity and type of biogenic amines produced is strongly influenced by the food composition, microbial flora and other characteristics, which promote bacterial growth during food storage [3].
\end{abstract}

By another hand, between numerous different species of clinical interest, neurotransmitters are ones the most studied compounds. They are compounds that have a very important role in the nervous system, because they are involved in the communication between neurons. Biogenic amines, comprising dopamine, norepinephrine, epinephrine and serotonin are neurotransmitters. These compounds have special roles in neuroscience. Dopamine is related to Parkinson's disease [4].
Epinephrine and norepinephrine have been a special interest in the origin of neurological tumors [5]. Serotonin (5-hydroxytryptamine) plays an important role in a variety of physiological functions (sleep regulation) and pathological states (such as psychiatric disorders, depressions, etc.) [6]. Medical and pharmaceutical research has developed on this field in order to elucidate the mechanisms and reasons for several neurological disorders, with the objective to open possibilities of pharmacological treatments in a disturbed system.

Many techniques have been developed and improved for detection and quantification of biogenic amines in biological fluids, comprising fluorimetry [3], thin layer chromatography with fiber optic detection [6] and chemiluminescence detection [7]. However, high-performance liquid chromatography (HPLC) with fluorimetric detection, electrochemical detection or combined fluorimetric and electrochemical detection, has been applied for neurotransmitter determinations [8]. However, these methods require extensive sample pre-treatments and expensive equipments.

Electrochemical detection, both qualitative and quantitative, of biogenic amines using chemically modified electrodes have been 
reported in the literature, as a good and inexpensive alternative for the traditional methods $[9,10]$.

However, another attractive alternative for biogenic amine determinations are the biosensors. They combine biological recognition through enzyme specificity with construction simplicity. Many biosensors for the detection of biogenic amines based on commercial or home-purified enzymes have been proposed in the literature $[11,12]$.

A key factor in the construction of a biosensor is the need to achieve optimal and effective enzyme immobilization. Several methods have been used for the immobilization of tyrosinase on to various substrates include carbon paste immobilization, sol-gel immobilization, physical adsorption, Langmuir-Blodgett thin films and electro-chemical entrapment of enzyme within polymer or composite matrix $[13,14]$. The use of conducting polymers for the fabrication of a range of biosensors has been studied extensively in last years due to their interesting properties. Polypyrrole thin films have been investigated by our group as sensing materials for voltammetric sensors in a diversity of applications [15-17]. Polypyrrole doped with different doping agents are unique in their capability to act as immobilization matrices for enzyme retention and electronic transducers. Consequently, polypyrrole has gained the most use for the fabrication of enzyme-based biosensors $[11,18]$.

In this study, it has been investigated the use of cross-linking immobilization of tyrosinase into polypyrrole as a basis for fabrication of a stable amperometric biosensor for biogenic amines. Cyclic voltammetry has been applied to study the detection of tyramine and dopamine. The response dependences and amperometric characteristics comprising sensitivity, kinetics, linear range, limits of detection and stability of the prepared enzyme electrode in the detection of amine compounds have been investigated.

\section{Experimental}

Materials

All the solutions were prepared using ultrapure water. All chemicals were of analytical grade and used without further purification

Mushroom tyrosinase (EC: 1.14.18.1 from mushroom, activity of $5370 \mathrm{U} \cdot \mathrm{mg}^{-1}$, CAS 900210-2) was purchased from Sigma Chemical Co. (USA). A $4.5 \mathrm{mg} \cdot \mathrm{mL}^{-1}$ solution of tyrosinase in buffer phosphate $0.01 \mathrm{M}(\mathrm{pH}=7)$ was employed for the enzyme immobilization.
Solutions of amine compounds including tyramine and dopamine were prepared by dissolving the corresponding compound in phosphate buffer 0.01M ( $\mathrm{pH}=7)$.

\section{Apparatus}

Electropolymerizations and electrochemical measurements were performed using an EG\&G Princeton Applied Research potentiostat /galvanostat (Model 263). A three-electrode electrochemical cell $(25 \mathrm{~mL})$ was used. All the electropolymerizations were carried out at a constant temperature $\left(20^{\circ} \mathrm{C}\right)$. An $\mathrm{Ag} / \mathrm{AgCl} / \mathrm{KCl}_{3 \mathrm{M}}$ electrode was used as reference electrode. The counter electrode was a large surface area platinum ( $2 \mathrm{~cm}^{2}$ surface area) gauze.

Preparation of phosphate-doped polypyrrole film $\left(\mathrm{PO}_{4}-\mathrm{Ppy} / \mathrm{Pt}\right)$

The polypyrrole film $\left(0.78 \mathrm{~mm}^{2}\right)$ was electrosynthesized on a $\mathrm{Pt}$ disk electrode from an aqueous solution including $0.1 \mathrm{M}$ pyrrole and $0.1 \mathrm{M}$ PBS, by chronopotentiometry at a fixed current of $60 \cdot 10^{-6} \mathrm{~A}$ for $15 \mathrm{~s}$. Once prepared, the modified polymeric electrodes were extracted from the synthesis solution and washed carefully. The thickness of the film obtained was about $2.7 \mu \mathrm{m}$ as calculated from the injected charge.

\section{Fabrication of biosensor (Tyr/PO ${ }_{4}-\mathrm{Ppy} / \mathrm{Pt}$ )}

The enzyme, tyrosinase (Tyr), was immobilized on the above electropolymerized Ppy film by a casting technique followed by cross-linking. $5 \mu \mathrm{l}$ of $0.01 \mathrm{M}$ phosphate buffer $(\mathrm{pH} 7.0)$ containing $4.5 \mathrm{mg} \cdot \mathrm{mL}^{-1}$ of tyrosinase, was added onto $0.78 \mathrm{~mm}^{2}$ area of polymer film. After drying, the Tyr/PO $/ \mathrm{PO}_{4}-\mathrm{Ppy}$ films were exposed to a $2.5 \%(\mathrm{v} / \mathrm{v})$ glutaraldehyde solution (in phosphate buffer $0.01 \mathrm{M}$ of $\mathrm{pH} 7$ ) for 20 minutes at room temperature. The enzyme-immobilized film was dried at $10^{\circ} \mathrm{C}$ and rinsed with phosphate buffer solution thrice to remove any unbound enzyme from the polymer film surface and was further dried at $10^{\circ} \mathrm{C}$ and stored at $4^{\circ} \mathrm{C}$.

\section{Results and discussions}

In this study polypyrrole (Ppy) thin films were electrosynthetized from an aqueous solution including 0.1 M pyrrole and 0.1 M PBS ( $\mathrm{pH} 7.0)$. The novel idea was to use a polypyrrole matrix doped with phosphate anions in order to reduce the doping-dedoping effect in the polymer layer during the electrochemical studies.

With the purpose of preparing high reproducible polypyrrole films chronopotentiometry technique was used. The optimal current for polypyrrole deposition was $60 \cdot 10^{-6} \mathrm{~A}$ and the polymerization time was $15 \mathrm{~s}$. The polypyrrole film obtained 
under these conditions has an optimal thickness for an efficient immobilization of the tyrosinase. Additionally, this thickness produces low capacitive currents, improving the sensitivity of the biosensor. The RSD (relative standard deviation) of polypyrrole preparation is lower than $5 \%$. The method used for tyrosinase immobilization consists in two steps: adsorption of enzyme within polypyrrole film and crosslinking with glutaraldehyde.

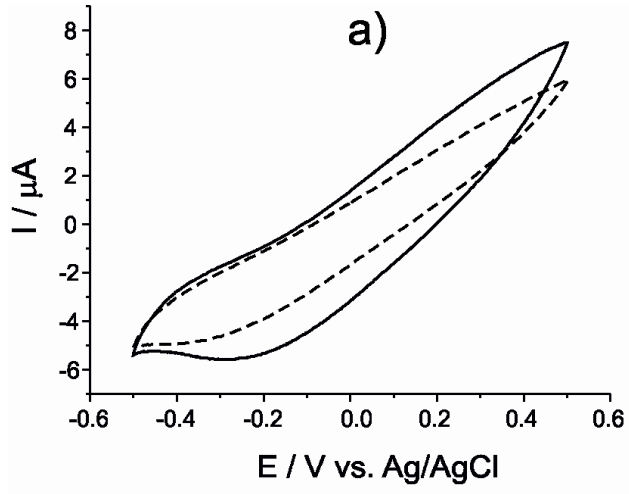

b)

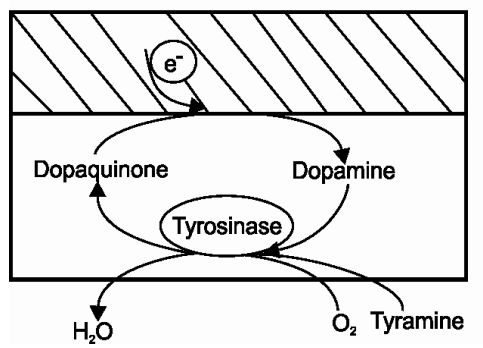

\section{Electrode \\ Immobilized enzyme \\ Solution}

Fig. 1: a) Cyclic voltammograms of Tyr/PO $\mathrm{P}_{4}-\mathrm{Ppy} / \mathrm{Pt}$ electrode in absence (dashed line) and in presence of $4 \cdot 10^{-4} M$ tyramine (solid line). b) Functioning scheme of the biosensor for the detection of tyramine.

Cyclic voltammograms of the $\mathrm{PO}_{4}-\mathrm{Ppy} / \mathrm{Pt}$ electrode immersed in tyramine or dopamine solution did not present any peak in the potential range studied. Therefore, for detection of such compounds immobilization of Tyr within polypyrrole film is necessary.

Figure 1a shows the $\mathrm{CV}$ of the $\mathrm{Tyr} / \mathrm{PO}_{4}-\mathrm{Ppy} / \mathrm{Pt}$ electrode before and after addition of tyramine in $0.01 \mathrm{M}$ PBS ( $\mathrm{pH} 7)$. The CV presents a well defined peak locating at $-0.250 \mathrm{~V}$, which was due to the reduction of dopaquinone species formed from the enzymatic reaction on the electrode surface (Figure 1b).

Kinetic studies were performed by registering the cyclic voltammograms of the $\mathrm{Tyr} / \mathrm{PO}_{4}-$ $\mathrm{Ppy} / \mathrm{Pt}$ biosensor in $10^{-4} \mathrm{M}$ dopamine solution at different scan rates, from 0.025 to $0.20 \mathrm{~V} \cdot \mathrm{s}^{-1}$. A linear regression equation for $y=-2 \cdot 10^{-5} x-$ $5 \cdot 10^{-6}$ with $R^{2}=0.9834$ is obtained. It was observed that peak height varies directly with the sweep rate, indicating that there is no diffusion limitation. From the slope of this line and using the Laviron equation:

$$
I=\frac{n^{2} F^{2} v A \Gamma}{4 R T}
$$

where $\Gamma$ is the surface coverage $\left(\mathrm{mol} \cdot \mathrm{cm}^{-2}\right), A$ is the electrode area $\left(\mathrm{cm}^{2}\right), v$ is the potential scan rate, the total surface coverage calculated was $5.53 \cdot 10^{-10} \mathrm{~mol} \cdot \mathrm{cm}^{-2}$.
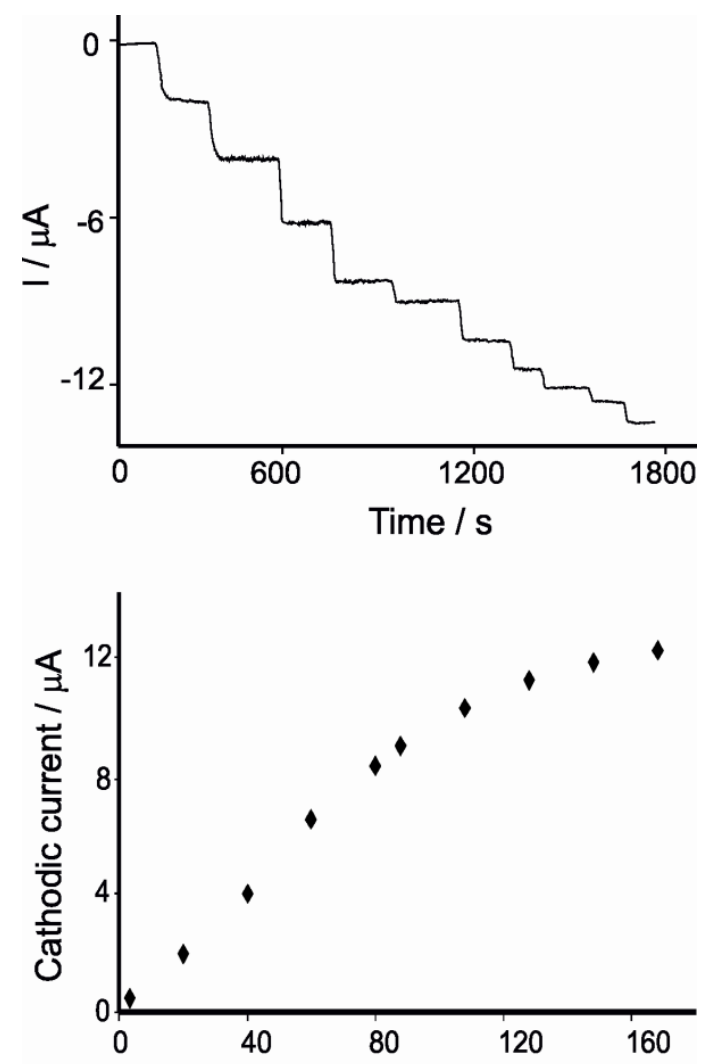

Time / s

Fig. 2: a) a) Amperometric response of biosensor to dopamine in $0.1 \mathrm{M}$ PBS solution $(\mathrm{pH}=7)$. Applied potential $-0.25 \mathrm{~V}$. b) The calibration curve between the reduction current and the concentration of dopamine in PBS (pH 7.0) at -0.25V.

Figure 2a illustrates a typical amperometric response for the $\mathrm{Tyr} / \mathrm{PO}_{4}-\mathrm{Ppy} / \mathrm{Pt}$ biosensor at $0.250 \mathrm{~V}$ after the addition of successive aliquots of dopamine to the $0.01 \mathrm{M}$ PBS $(\mathrm{pH} 7.0)$ under constant stirring.

A well-defined reduction current proportional to the concentration of biogenic amine is observed, which results from the electrochemical reduction of o-dopaquinone species enzymatically formed.

The Tyr $/ \mathrm{PO}_{4}-\mathrm{Ppy} / \mathrm{Pt}$ electrode achieves $95 \%$ of steady-state current in almost $6 \mathrm{~s}$. The response rate is much faster than that of $10 \mathrm{~s}$ reported in a conducting polymer film [19] and $50 \mathrm{~s}$ 
reported in the pure silica sol-gel matrix [20]. Such fast response is attributed to a rapid electron transfer between the enzymaticallyproduced dopaquinone and the biosensor.

Figure 2 b) showed the relationship between the response current of the biosensor and the dopamine concentration in PBS (pH 7.0) at $-0.25 \mathrm{~V}$ (calibration curve). The enzyme kinetic parameters and the analytical characteristics listed in Table 1.
As can be observed, for the amine compounds analyzed, the kinetics of the enzymatic reaction fitted into a Michaelis-Menten type kinetics (h 1). The sensitivity followed the decreasing order dopamine $>$ tyramine. The greater value of $I_{\max }$ and the lowest $K_{M}^{a p p}$ was found for dopamine. The detection limits were $0.88 \mu \mathrm{M}$ for dopamine and $4.68 \mu \mathrm{M}$ for tyramine.

Tab. 1: Response characteristics of the Tyr/PO ${ }_{4}-P p y / P t$ biosensor to amine compounds

\begin{tabular}{|c|c|c|c|c|c|c|}
\hline Compound & $\mathrm{h}$ & Linear range $/ \mu \mathrm{M}$ & Detection limit $/ \mu \mathrm{M}$ & $\mathrm{R}^{2}$ & $\mathrm{I}_{\max } / \mu \mathrm{A}$ & $K_{M}^{\text {app }} / \mu \mathrm{M}$ \\
\hline Dopamine & 1.02 & $2-100$ & 0.88 & 0.9987 & 12.24 & 62.65 \\
\hline Tyramine & 0.96 & $4-160$ & 4.68 & 0.9964 & 6.45 & 88.74 \\
\hline
\end{tabular}

\section{Conclusion}

This study has demonstrated the possibility of developing a polypyrrole based biosensor for monitoring tyramine and dopamine in aqueous medium. Furthermore, it has confirmed that the conducting polypyrrole having phosphate doping anion inserted over it can be utilized as an appropriate matrix for the immobilization of tyrosinase. The biosensor reveals fast response rate and high sensitivity for the amperometric detection of tyramine and dopamine.

\section{Acknowledgments}

This work was supported by a grant of the Romanian National Authority for Scientific Research, CNCS - UEFISCDI, project number PN-II-ID-PCE-2011-3-0255.

\section{References}

[1] M. Nuñez, M. Medina, Biogenic Amines, Encyclopedia of Dairy Sciences, 451-456 (2011)

[2] S. Tahmouzi, R. Khaksar, M. Ghasemlou, Food Chem. 126, 756-761 (2011); doi: 10.1016/j.foodchem.2010.11.060

[3] A. Halasz, A. Barath, L.S. Sarkadi, W. Holzapfel, Trends Food Sci. Technol. 5, 42-49 (1994); doi: 10.1016/0924-2244(94)90070-1

[4] J. Lotharius, P. Brundin, Nat. Rev. Neurosci. 3, 932-942 (2002); doi:10.1038/nrn983

[5] S.G. Palop, A.M. Romero, J.M. Calatayud, J. Pharm. Biomed. Anal. 27,1017-1025 (2002); doi: 10.1016/S0731-7085(01)00610-0

[6] R.L. Aponte, J.A. Diaz, A.A. Pereira, V.G. Diaz, J. Liq. Chromatogr. Relat. Technol. 19, 687-698 (1996); DOI:10.1080/10826079608005530

[7] F.N. Chen, Y.X. Zhang, Z.J. Zhang, Chinese Journal of Chemistry 25, 942-946 (2007; DOI: $10.1002 /$ cjoc. 200790183
[8] K. J. Huang, C.X. Jin, S.L. Song, C.Y. Wei, Y.M. Liu, J. Li, J Chrom B 879, 579-584 (2011); doi: 10.1016/j.jchromb.2011.01.018

[9] M.L. Rodríguez-Méndez, M. Gay, C. Apetrei, J.A. De Saja, Electrochim. Acta 54, 7033-7041 (2009); doi: 10.1016/j.electacta.2009.07.024

[10] M.D. Rubianes, G.A. Rivas, Anal. Chim. Acta 440, 99-108 (2001); doi: 10.1016/S00032670(01)01059-5

[11] C. Apetrei, M.L. Rodríguez-Méndez, J.A. De Saja, Electrochim. Acta 56, 8919-8925 (2011); doi: 10.1016/j.electacta.2011.07.127

[12] T.J. Castilho, M. del Pilar Taboada Sotomayor, L.T. Kubota, J. Pharm. Biomed. Anal. 37, 785-79 (2005); doi: 10.1016/j.jpba.2004.11.043

[13] C. Apetrei, P. Alessio, C.J.L. Constantino, J.A. de Saja, M.L. Rodriguez-Mendez, F.J. Pavinatto, E. G. Ramos Fernandes, V. Zucolotto, O.N. Oliveira Jr., Biosens. Bioelectron 26, 2513-2519 (2011); doi: 10.1016/j.bios.2010.10.047

[14] Q. Ameer, S.B. Adeloju, Sens. Actuators B 140, 5-11 (2009); doi: 10.1016/j.snb.2009.03.056

[15] V. Parra, A.A. Arrieta, J.A. Fernández-Escudero, H. García, C. Apetrei, M.L. Rodríguez-Méndez, J.A. de Saja, Sens. Actuators B 115, 54-61 (2006); doi: 10.1016/j.snb.2005.08.040

[16] M.L. Rodríguez-Méndez, C. Apetrei, J.A. de Saja, Electrochim. Acta 53, 5867-5872 (2008); doi: 10.1016/j.electacta.2008.04.006

[17] A.A Arrieta, C Apetrei, M.L Rodríguez-Méndez, J.A de Saja, Electrochim. Acta 49, 4543-4551 (2004); doi: 10.1016/j.electacta.2004.05.010

[18] Rajesh, W. Takashima, K. Kaneto, React. Funct. Polym. 59, 163-169 (2004); doi: 10.1016/j.reactfunctpolym.2004.08.009

[19] P. Wang, M. Liu, J. Kan, Sens. Actuators B 140, 577-584 (2009); doi: 10.1016/j.snb.2009.05.005

[20] J. Li, L.S. Chia, N.K. Goh, S.N. Tan, Anal. Chim. Acta 362, 203-211 (1998); doi: 10.1016/S00032670(98)00064-6 